\title{
Finite Element Modeling and Simulation of Electromagnetic Crimping of Al6016-T6 Tube with Steel Rod
}

\author{
G. Areda $^{1 *}$, S. Kore ${ }^{2}$ \\ ${ }^{1}$ Research Scholar, ${ }^{2}$ Assiciate Professor, Indian Institute of Technology Guwahati, India \\ \{a.getu@iitg.ernet.in\}
}

\begin{abstract}
Numerical modeling and simulation of an electromagnetic crimping process will give us better insight how different phenomenon relate and affect the result of deformation significantly. This paper focuses on modeling and simulating of electromagnetic crimping of Al6016-T6 tube on a steel rod with single and double rectangular groove. In addition, predicting of velocity, effective plastic strain along joining zone and radial displacement of elements using current curve from the experimental investigation will be main goal. Effects of process parameters on electromagnetic crimping of Al tube are discussed in detail. FEM results are obtained from 3D simulations with the help of EM module in LS-DYNA ${ }^{\mathrm{TM}}$ in which finite element method (FEM) for a conductor and Boundary element method (BEM) for surrounding air is implemented.
\end{abstract}

Keywords: Electromagnetic crimping, FEM, LS-DYNA, Radial displacement

\section{Introduction}

While high current pulse passed through a coil by the discharge of a capacitor bank, the electromagnetic field developed which in turn induces current to a nearby conductor. Magnetic pressure would be generated due to the reaction of two opposed magnetic field. The radial force generated would be able to deform workpiece plastically. One of the joining partners should have good electrical conductivity to get good deformation. An optimal design for a mandrel with two grooves used for axially loaded joints with the aid of FEM simulation and experimental studies are determined by Vanhulsel, Pieter, et al. [1]. Zhang and Peihui [2] design an electromagnetic experiment and prove the high strength of tubular crimping joints; joints control parameters was analyzed and understood by measuring strain distribution in the tubes. Influence of coil length on the waveform of coil current pulse, a peak value of equivalent magnetic pressure, magnetic force, deformation characteristics of the tube and energy efficiency during electromagnetic tube compression using analytical and sequential coupling numerical simulation approach have been studied by $\mathrm{Yu}$, Hai-ping, and Chun-Feng Li [3]. The capability of Electromagnetism (EM) module of LS-DYNA for numerically solving and simulating EMF problem for designing of the systems by comparing with the result found experimentally has been assessed by Jianhui Shang et al. [4]. Three-dimensional coupled simulation of steel to steel EM torque joining process using LS-DYNA an EM-module in a beta version of the structural explicit code and verification with the experimental result was carried out by R. Neugebauer, et al. [5]. In this work, simulations were run to investigate electromagnetic crimping process of the Al6006-T6 tube of $0.5 \mathrm{~mm}$ thickness on profiled steel rod which is assumed rigid. Double and single rectangular groove is a profile designed on the steel rod. Deformation on the steel profiled rod was assumed to be zero, for simplicity.

\subsection{Johnson-Cook material model}

This material model is particularly suited to a model which involve high strain rate deformation of metals. It is generally used in an adiabatic transient dynamic analysis. The hardening is a particular type of isotropic hardening in which the yield stress $\sigma_{\mathrm{Y}}$ is assumed to be of the form of Eq. (1) and used to relate $\sigma, \varepsilon, \dot{\varepsilon}^{*}$ and temperatures as discussed by L.Schwer [6]

$$
\sigma_{y}=\left(A+B \bar{\varepsilon}^{p^{n}}\right)\left(1+c \ln \dot{\varepsilon}^{*}\right)\left(1-\left(\frac{T-T_{R}}{T_{m}-T_{R}}\right)^{m}\right)
$$

B. Iyer, S. Nalbalwar and R. Pawade (Eds.)

ICCASP/ICMMD-2016. Advances in Intelligent Systems Research.

Vol. 137, Pp. 83-88.

(C) 2017. The authors - Published by Atlantis Press

This is an open access article under the CC BY-NC license (http://creativecommons.org/licens)es/by-nc/4.0/). 
Where $A$ and $B$ yield strength parameters, $C$ strain rate sensitivity, $\varepsilon^{-p^{n}}$ equivalent plastic strain, $\dot{\varepsilon}^{*}$ equivalent plastic strain rate of workpiece, $n$ strain hardening index, $m$ thermal softening index, $T_{R}$ room temperature, and $T_{m}$ melting temperature of the workpiece, Toperating temperature.

\section{FEM of Electromagnetic Crimping Using Double and Single Rectangular Groove}

Al6061-T6 tube with outer diameter of $17 \mathrm{~mm}$, wall thickness of $0.5 \mathrm{~mm}$ and $75 \mathrm{~mm}$ length is designed as joining partners with the steel rod which has geometrical shape and dimension as shown in Fig. 1 below.
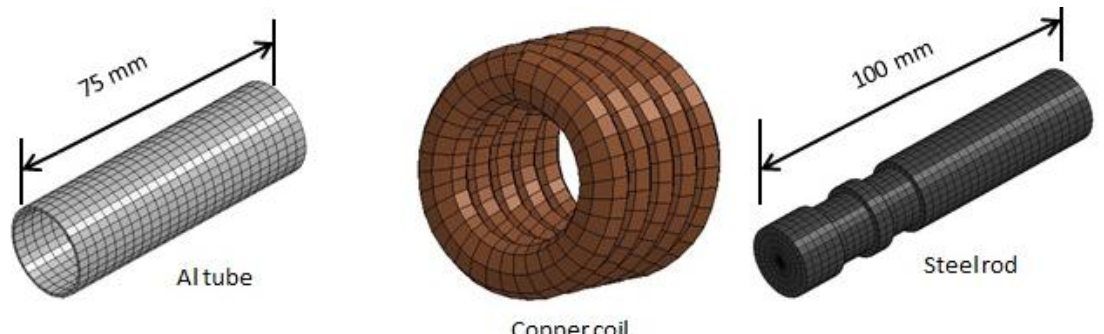

Fig. 1. Modelling of workpieces and coil

The profile machined on steel rod has two rectangular grooves with a width of $10 \mathrm{~mm}$, depth $1.5 \mathrm{~mm}$, and $4 \mathrm{~mm}$ collar. Tube, coil and steel rod have meshed using hexahedral solid elements .Tube, steel rod and coil meshed with an element of 3040, 8240 and 688 for double rectangular groove model, and 4000, 9246, and 920 elements for single rectangular groove model. Parameters used in the simulation for Jhonson-Cook material model for Al6061-T6, and of a linear polynomial equation are summarized in Table1 and 2 [7]. Material properties of Al6061-T6 and Copper are summarized in Table 3 and in Table 4 [8].Geometrical setup of coil and workpieces used in the simulation is shown in Fig. 2 after proper meshing. The simulation of electromagnetic crimping of Al6061-T6 tube is carried out with the help of EM module in LS-DYNA ${ }^{\text {TM }}$.

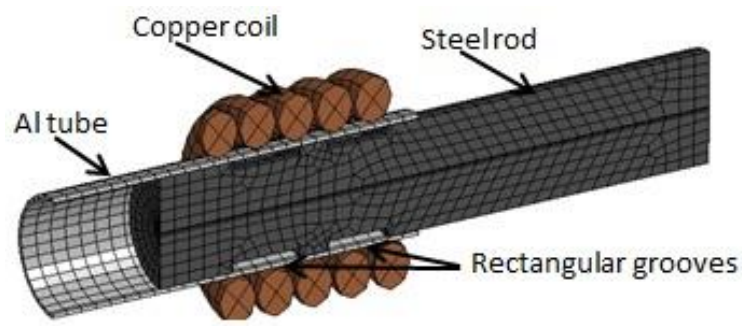

Fig. 2. Illustration of the model developed for simulation in LS-DYNA EM module

Table 1 Parameters of Jhonson-Cook strength model for Al6061-T6 [7]

\begin{tabular}{|c|c|c|c|c|c|c|}
\hline $\boldsymbol{A}(\boldsymbol{M P a})$ & $\boldsymbol{B}(\boldsymbol{M P a})$ & $\boldsymbol{C}$ & $\boldsymbol{n}$ & $\boldsymbol{m}$ & $\boldsymbol{T}_{\boldsymbol{m}}(\boldsymbol{K})$ & $\dot{\boldsymbol{\varepsilon}}\left(\mathbf{s e c}^{-1}\right)$ \\
\hline 324 & 114 & 0.002 & 0.42 & 1.34 & 925 & 1 \\
\hline
\end{tabular}

Table 2 Parameters for Linear Polynomial EOS for Al6061-T6 [7]

\begin{tabular}{|c|c|c|c|c|c|c|c|c|}
\hline $\boldsymbol{C}_{\boldsymbol{0}}$ & $\boldsymbol{C}_{\boldsymbol{I}}$ & $\boldsymbol{C}_{\boldsymbol{2}}$ & $\boldsymbol{C}_{\boldsymbol{3}}$ & $\boldsymbol{C}_{\boldsymbol{4}}$ & $\boldsymbol{C}_{\boldsymbol{5}}$ & $\boldsymbol{C}_{\boldsymbol{6}}$ & $\boldsymbol{E}_{\boldsymbol{0}}$ & $\boldsymbol{V}_{\boldsymbol{0}}$ \\
\hline 0 & $74.2 \mathrm{GPa}$ & $60.5 \mathrm{GPa}$ & $36.5 \mathrm{GPa}$ & 1.96 & 0 & 0 & 0 & 1 \\
\hline
\end{tabular}


Table 3 Properties of Al6061-T6 [8]

\begin{tabular}{|c|c|c|c|}
\hline Density $(\rho)$ & $2700 \mathrm{~kg} / \mathrm{m}^{3}$ & Heat Capacity $(C)$ & $8.96 \mathrm{~J} / \mathrm{kg}-\mathrm{K}$ \\
\hline Modulus of rigidity $(\mathrm{G})$ & $26 \mathrm{GPa}$ & Thermal Conductivity $(K)$ & $126 \mathrm{~W} / \mathrm{m}-\mathrm{K}$ \\
\hline Modulus of Elasticity(E) & $68.9 \mathrm{GPa}$ & Electrical Conductivity $(\sigma)$ & $25 \mathrm{MS} / \mathrm{m}$ \\
\hline Poisson's Ratio $(\gamma)$ & 0.33 & Melting Temperature $\left(T_{m}\right)$ & $925 \mathrm{~K}$ \\
\hline
\end{tabular}

Table 4 Material properties Cu1001 used in simulation [8]

\begin{tabular}{|l|l|l|l|}
\hline Conductivity $(\sigma)$ & $5.96 \times 10^{7} \mathrm{~S} / \mathrm{m}$ & Young's Modulus $(\mathrm{E})$ & $124 \mathrm{GPa}$ \\
\hline Density $(\rho)$ & $8960 \mathrm{~kg} / \mathrm{m}^{3}$ & Poisson ratio $(\gamma)$ & 0.27 \\
\hline
\end{tabular}

Table 5 Simulation conditions

\begin{tabular}{|l|l|l|l|}
\hline Total time taken for the simulation & $600 \mu \mathrm{sec}$ & Thermal time step & $2 \mu \mathrm{sec}$ \\
\hline Excitation current supplied & $400 \mu \mathrm{sec}$ & Mechanical time step & $30 \mathrm{~ns}$ \\
\hline Intial temperature & 300 & Electromagnetic time step & $2 \mu \mathrm{sec}$ \\
\hline Total input energy & $4.7 \mathrm{~kJ}$ & & \\
\hline
\end{tabular}

Total Computational time of the process is $29 \mathrm{~min}$.

\section{Results and Discussion}

Figure 3(a) shows the shape of electromagnetically crimped Aluminium tube on steel profiled rod obtained experimentally. Figure 3(b) shows 3D simulation result which is obtained for electromagnetic crimping of Al6061-T6 tube on the steel rod with double rectangular groove. Groove made on steel is filled with the tube due to sufficient amount of energy for both cases.

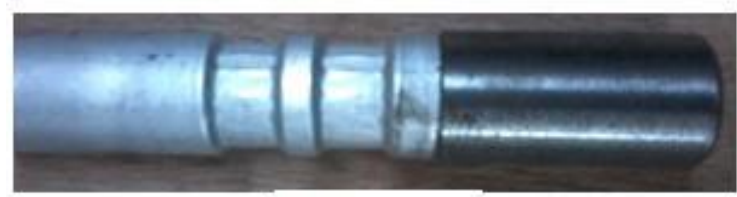

(a)

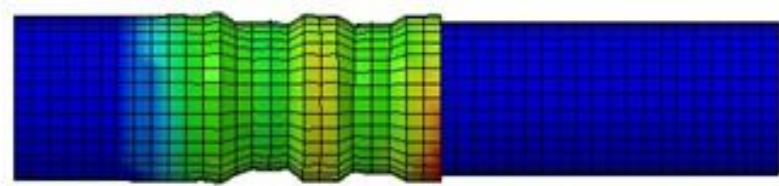

(b)

Fig. 3. (a) Experimentally crimped sample (b) 3D simulation of EM crimping

3.1 Resultant displacement and effective plastic strain incase of double rectangular groove

Maximum resultant displacement associated with an element B (2163) and D (2606) which are located normal to the grooves is $1.454 \mathrm{~mm}$ and $1.35 \mathrm{~mm}$ respectively. The minimum displacement is shown for an element $\mathrm{A}$ (2617), E (2603) and C (2610) that is below $0.4 \mathrm{~mm}$ which are located at the end and collar part of joining zone. The change in the magnetic field over time due to damped sinusoidal current waveform cause waviness as shown in Fig. 4(a). In 3D simulation peak effective plastic strain at element D (2606) is 0.531 which is reached at $120 \mu \mathrm{sec}$. As shown from Fig. 4(b) effective plastic strain get less for elements far from the center. 

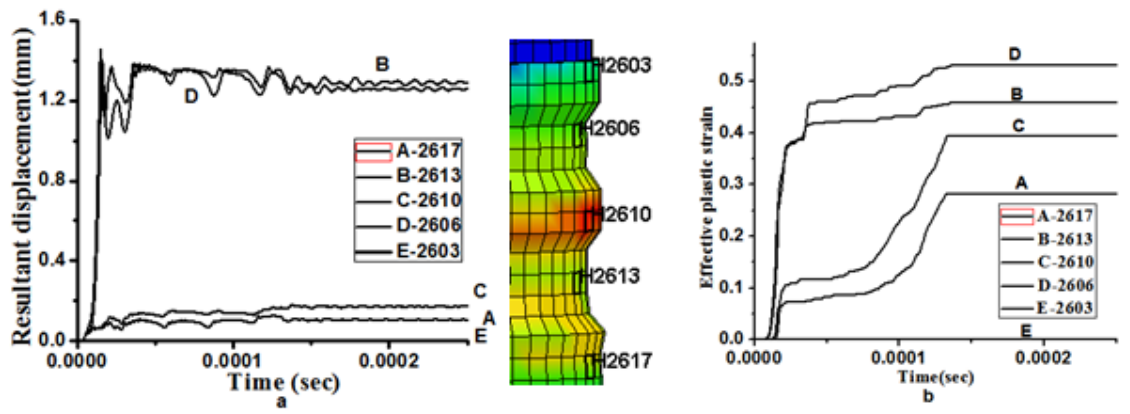

Fig. 4. (a) Resultant displacement versus time for various elements at $70 \%$ (4.7kJ) energy (b) Effective plastic strain versus time for different element at room temperature

\subsection{Temperature and Von-misses stress for double rectangular groove}

Temperature variation with respect to time for different element obtained from 3D simulation is shown in Fig. 5(a).
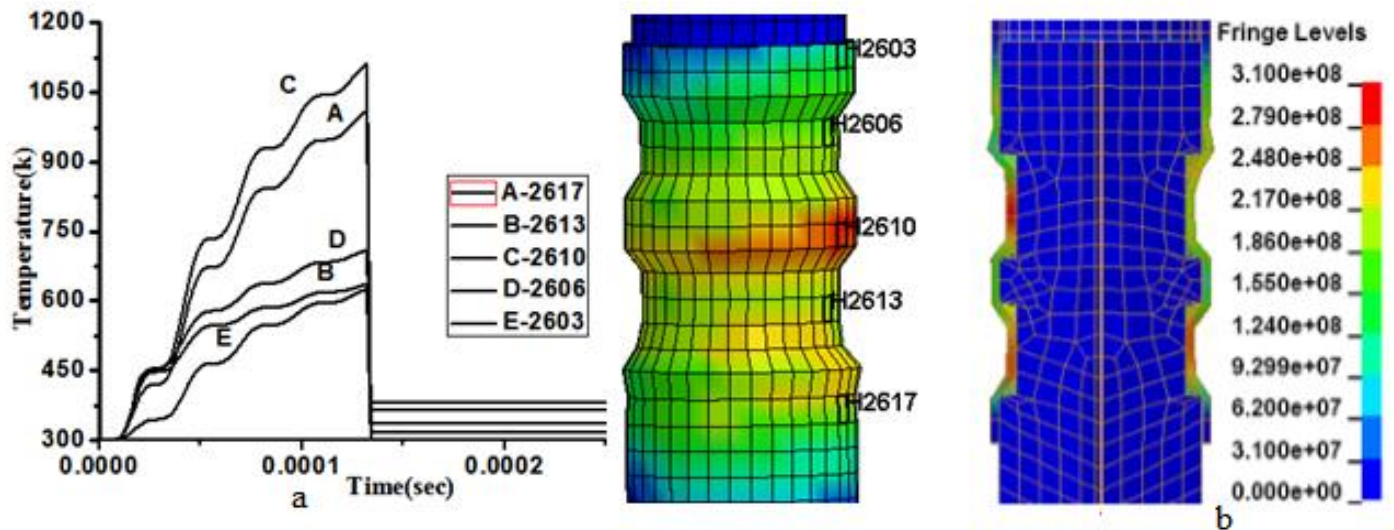

Fig. 5. (a) Temperature versus time for $70 \%$ energy using double groove (b) Von misses stress

The increment of temperature while deformation was continued can be predicted using 3D simulation as shown in Fig. 5(a). Maximum and minimum temperature is associated with an element C (2610) and E (2603) located parallel to the groove. Predicted maximum and minimum temperature is $1111.1 \mathrm{k}$ and $299.9 \mathrm{k}$. The fringe level shown in Fig. 5(b) describe von misses stress obtained using $4.7 \mathrm{~kJ}$ at the end of process termination. The maximum von misses stress with the magnitude of $310 M P a$ obtained on an element located in the groove.

\subsection{Resultant velocity and Radial displacement for single rectangular groove}

Resultant velocitywas predictedfor different element along joining zone using a 3D simulation of electromagnetic crimping for single rectangular groove at $50 \%(2.3 \mathrm{~kJ})$ energy. Figure 6(a) shows that the maximum velocity obtained for an element located at the center of the groove $\mathrm{C}(758)$ is $275.82 \mathrm{~m} / \mathrm{sec}$. Minimum velocity predicted is less than $50 \mathrm{~m} / \mathrm{sec}$ for those elements located at the end of joining zone like element A (752) and B (755) .Resultant displacement of the different element along joining zone at the end of deformation using an energy of $2.3 \mathrm{~kJ}$ is shown in Fig. 6(b) below. 

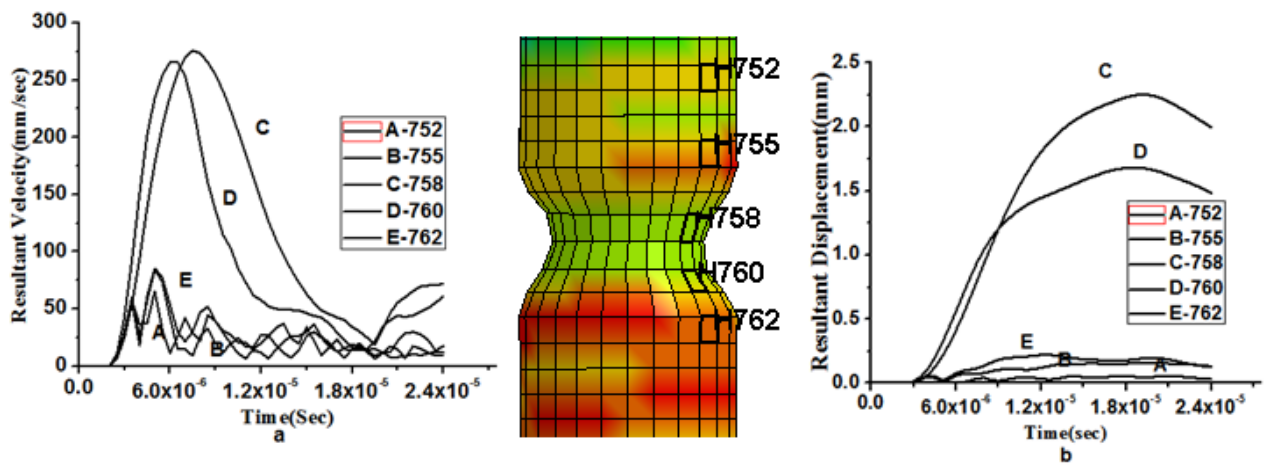

Fig. 6. (a) Resultant velocity versus time at $50 \%$ of energy (b) Radial displacement versus time at $50 \%$ of energy

Maximum resultant displacement is associated with an element located at the center of joining zone C (758), and minimum displacement is associated with an element located at the end of joining zone $\mathrm{E}$ (762). Element $\mathrm{C}$ (758) displaced $2.25 \mathrm{~mm}$ and element E (762) displaced by an amount of $0.125 \mathrm{~mm}$.

\subsection{Effective plastic strain and temperature prediction for single rectangular groove}

Effective plastic strains along joining zone for different elements are shown in Fig.7 (a). Maximum effective strain goes to element $\mathrm{C}$ (758) that is 0.455 and minimum effective strain is associated with an element A (752) located at the end of joining zone. For the matter of discussion we can see how temperature is varying with respect to simulation time at $2.3 \mathrm{~kJ}$. Variation in temperature for different element along joining zone is shown in Fig.7 (b).

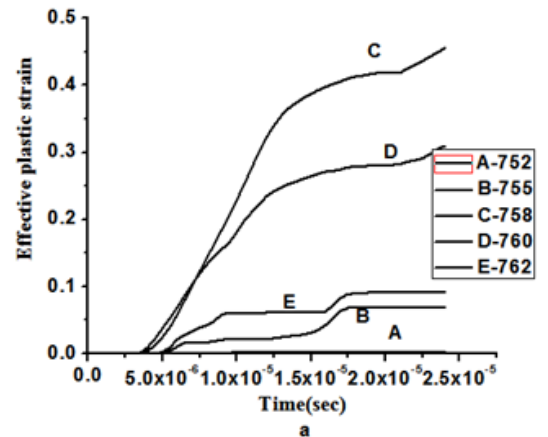

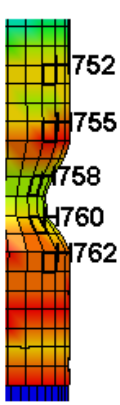

762

2

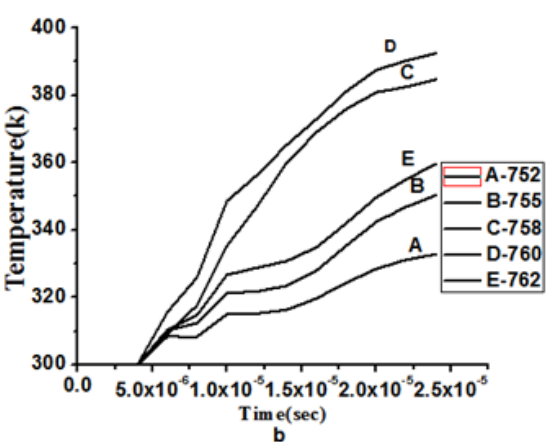

Fig. 7. (a) Effective plastic strain versus time at 50\% of energy (b) Temperature versus time for $50 \%$ of energy

Temperature varies from $300 \mathrm{k}$ to $392.49 \mathrm{k}$. Element located at the center of the groove D (760) is associated with highest temperature. Element located at the end of joining zone A (752) has the lowest temperature. The highest the energy the higher the temperature and vice versa.

3.5 Comparison of resultant displacement and effective plastic strain versus time at different crimping energy for single rectangular groove

The magnitude of resultant displacement and effective plastic strain increase as energy is increasing. Resultant displacement with respect to time for a range of energy is shown in Fig. 8(a). An energy of more than $70 \%$ for considered geometry and material system results decreasing in resultant displacement. However, effective plastic strain is increasing as energy increases as shown in Fig.8(b). 


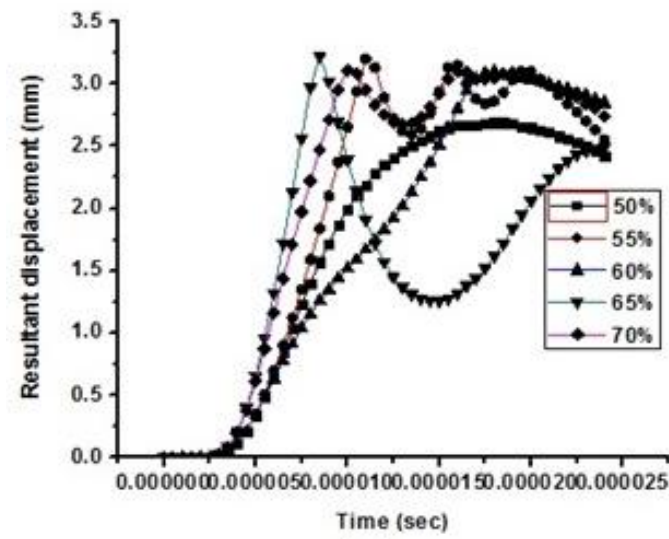

(a)

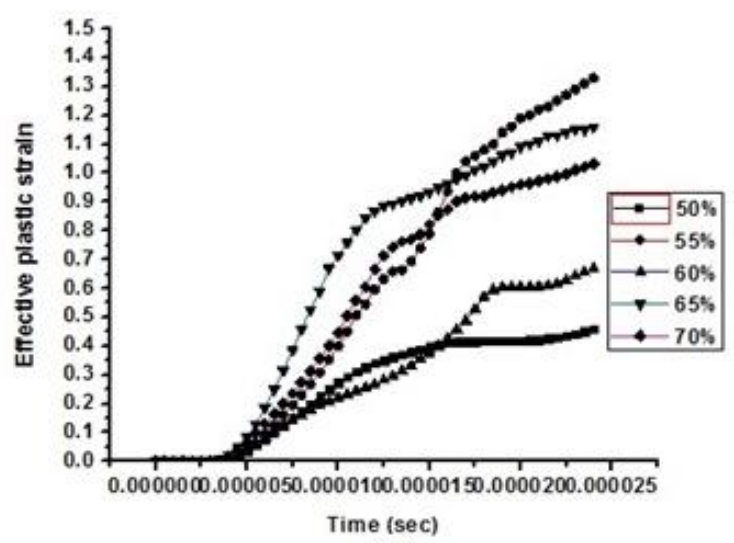

(b)

Fig. 8. (a) Resultant displacement versus time(b) effective plastic strain versus time

\section{Conclusions}

Electromagnetic crimping process is carried out in few microseconds and it is difficult to find out the strain behavior of deformed workpieces, velocity of workpiece, and deformation pattern experimentally. This modeling is mainly focusing on estimating these parameters numerically. Percentage of groove filling at $70 \%$ of energy was almost similar in both experimental and numerical analysis in the case of double rectangular groove. Mathematical modeling of the involved parameters in electromagnetic crimping is a complex task, but we can easily figure out the relation between those parameters using numerical modeling. From the above 3D simulation result, we can clearly understand the prediction capability of LS-DYNA EM module for several process parameters.

\section{References}

[1]. Vanhulsel Pieter, Matthias Van Wonterghem, Wim De Waele, and Koenraad Faes,"Groove design for form fit joints made by electromagnetic pulse crimping," In Sustainable Construction and Design Ghent University, Laboratory Soete, (SCAD), vol. 2, no. 3, (2011)432-441.

[2]. Zhang Peihui., "Joining enabled by high velocity deformation," Diss. The Ohio State University, 2003.

[3]. Yu Hai-ping, and Chun-Feng Li., "Effects of coil length on tube compression in electromagnetic forming," Transactions of nonferrous metals society of China 17.6, (2007)1270-1275.

[4]. Shang Jianhui, Pierre L'Eplattenier, Larry Wilkerson, and Steve Hatkevich., "Numerical Simulation and Experimental Study of Electromagnetic Forming," In 11th International LS-DYNA Users Conference, (2010) 10-27.

[5]. Neugebauer R., V. Psyk, and C. Scheffler.,"Simulation of electromagnetically formed joints," Chemnitz University of Technology, Germany. ICHSF, (2012) 219-228.

[6]. L.Schwer, "Optional Strain-Rate forms for the Johnson-Cook Constitutive Model and the Role of the Parameter," Epsilon_0, LS-DYNA Anwenderforum, LS-DYNA Frankenthal, (2007) 1-14.

[7]. Schwer L. E., \& Windsor, C. A., ," Aluminum plate perforation: a comparative case study using Lagrange with erosion, multi-material ALE, and smooth particle hydrodynamics," In Proc. from the 7th European LS-DYNA Conference, 2009.

[8]. MatWeb Material Property Data. Available from: http://www.matweb.com/ (date 10-06-2012). 